\title{
Laparoscopically Removed Streak Gonad Revealed Gonadoblastoma in Frasier Syndrome
}

\author{
KAZUNORI HASHIMOTO ${ }^{1}$, YU HORIBE ${ }^{1}$, JIRO EZAKI ${ }^{2}$, TOSHIYUKI KANNO ${ }^{1}$, NOBUKO TAKAHASHI ${ }^{1}$, \\ YOSHIKA AKIZAWA ${ }^{1}$, HIDEO MATSUI ${ }^{1}$, TOMOKO YAMAMOTO ${ }^{2}$ and NORIYUKI SHIBATA ${ }^{2}$ \\ Departments of ${ }^{1}$ Obstetrics and Gynecology, and ${ }^{2}$ Pathology, Faculty of Medicine, \\ Tokyo Women's Medical University, Tokyo, Japan
}

\begin{abstract}
Background: Frasier syndrome (FS) is characterized by gonadal dysgenesis and progressive nephropathy caused by mutation in the Wilm's tumor gene (WT1). We report a case of FS in which diagnosis was based on amenorrhea with nephropathy, and laparoscopicallyremoved streak gonad which revealed gonadoblastoma. Case Report: At the age of 3 years, the patient developed nephrotic syndrome. This later became steroid-resistant and, by the age of 16 years, had progressed to end-stage renal failure with peritoneal dialysis. At the age of 17 years, the patient presented primary amenorrhea and was referred to our department. Physical examination was consistent with Tanner 1 development and external genitalia were female phenotype. Speculum examination showed uterine cervix and uterine body and bilateral ovaries were not palpable on pelvic examination. Multi-sliced computed tomography of abdomen and pelvis revealed streaked structure along the bilateral external iliac artery at pelvic wall and hypoplastic uterus. Serum testing revealed primary hypogonadism pattern, elevated follicle-stimulating hormone and luteinizing hormone with low concentrations of estradiol and testosterone. The patient underwent genetic counseling with her parents. Chromosomal status was $46 X Y$ karyotype and DNA sequencing confirmed FS due to a heterozygous WTI mutation $(I V S 9+5 G>A)$. Elective laparoscopic bilateral salpingo-oophorectomy was performed to avoid increased risk for gonadoblastoma. Pathological examination revealed gonadoblastoma in the right gonad. Conclusion: Although a rare disease, the diagnosis of FS should be considered in the
\end{abstract}

Correspondence to: Kazunori Hashimoto, Department of Obstetrics and Gynecology, Faculty of Medicine, Tokyo Women's Medical University, Tokyo, Japan. Tel: +81 0333538111, Fax: +81 352697350, e-mail: hashimoto.kazunori@twmu.ac.jp

Key Words: Fraiser syndrome, gonadoblastoma, streak gonad, WT1 gene mutation, case report. case of primary amenorrhea with nephropathy. Prophylatic gonadectomy is recommended due to the high risk of gonadoblastoma in the dysgenetic gonad.

Frasier syndrome (FS) is characterized by male pseudohermaphroditism and nephropathy, and was first described in 46, XY monozygotic twins in 1964 (1). FS is caused by heterozygous de novo intronic splice site mutations in the Wilms' tumor suppressor gene (WT1), which is a regulator of early gonadal and renal development (2).

We report here a case of FS diagnosed based on amenorrhea with nephropathy, and laparoscopically removed streak gonad which revealed gonadoblastoma. This report was approved by the Institutional Review Board of Tokyo Women's Medical University and informed consent was given by the patient and her parents.

\section{Case Report}

A 16-year-old girl was referred for consultation by a nephrologist for the evaluation of primary amenorrhea. At the age of 4 she was suffering from infectious mononucleosis and found to have proteinuria; a renal biopsy specimen diagnosed membranous nephropathy. She developed nephrotic syndrome that was resistant to corticosteroid therapy. At 16 years of age, the patient had progressed to end-stage renal failure and peritoneal dialysis had started. Before awaiting kidney transplantation, she was referred to our Department for consultation. Physical examination was consistent with Tanner stage 1 development and external genitalia were female phenotype. Speculum examination showed uterine cervix and uterine body and bilateral ovaries were not palpable on pelvic examination. Multi-sliced computed tomography of abdomen and pelvis revealed streaked structure along the bilateral external iliac artery at the pelvic wall and hypoplastic uterus. Serum testing revealed a pattern of primary hypogonadism, with elevated follicle- 
stimulating hormone (346.7 $\mathrm{mIU} / \mathrm{ml})$ and luteinizing hormone $(165.7 \mathrm{mIU} / \mathrm{ml})$, with low concentrations of estradiol $(<10 \mathrm{pg} / \mathrm{ml})$, testosterone $(8.6 \mathrm{ng} / \mathrm{dl})$. The patient had counseling with her parents at our Center for Medical Genetics. The patient's chromosomal status was 46XY karyotype and DNA sequencing confirmed FS due to a heterozygous $W T 1$ gene mutation (IVS9+5G>A).

The patient underwent laparoscopic surgery which revealed a hypoplastic uterus, and bilateral long slender fallopian tube-like structures (Figure 1). There was a small amount of ascites and no peritoneal dissemination. Bilateral gonadectomy and salpingectomy was performed. The cytology of the ascites was negative and histopathological examination revealed gonadoblastoma in the right gonad. The patient's growth in stature had already halted. After the surgery, she received cyclic hormone therapy (HT) using conjugated equine estrogen at a dosage of $0.625 \mathrm{mg}$ /day for 30 days and dydrogesterone at a dosage of $10 \mathrm{mg} /$ day for 10 days. Withdrawal bleeding occurred following HT. Bone mineral density (BMD) was measured using dual energy $\mathrm{X}$ ray absorptiometry (Hologic QDR 4500; Bedford, MA, USA). BMD of lumbar spine (L2-L4) before HT and 1 year after HT was $0.743 \mathrm{~g} / \mathrm{cm}^{2}$ (T-score $71 \%$ ) and $0.792 \mathrm{~g} / \mathrm{cm}^{2}$ (T-score $75 \%$ ), respectively.

Pathological findings. Specimens from the gonads were fixed in phosphate-buffered formaldehyde and processed into paraffin blocks. Paraffin sections were routinely stained with hematoxylin and eosin (H-E).

Histopathological examination revealed a tumor in the right gonad consisting of cellular nests of tumor cells surrounded by fibrous stroma and with foci of calcification (Figure 2). The nests consisted of an admixture of large, round germ cells with pale cytoplasm and large vesicular nuclei, and smaller oval cells with deeply staining nuclei of granulosa or Sertoli cells. Some of the cells enclosed eosinophilic material forming Call-Exner-like bodies (Figure 3). A histopathological examination of the left gonad revealed only a microscopic focus of ovarian fibrotic stroma with no germ cells

Immunohistochemical staining of $\alpha$-inhibin (Clone R1, M3609, 1:50; Dako, Glostrup, Denmark) and placental alkaline phosphatase (A268, 1:100; Dako) was performed on 3 - $\mu$ m-thick sections cut from the paraffin-embedded specimen. Microwave antigen retrieval with Tris-EDTA (pH 9.0) was performed for $\alpha$-inhibin.

In the immunohistochemistry of gonadoblastoma cells, smaller cells of sex cord origin positive for $\alpha$-inhibin, as an ovarian stromal marker, and the large germ cells were negative for $\alpha$-inhibin (Figure 4A). On the other hand, staining for placental alkaline phosphatase was positive in the germ cells, but the sex cord type cells remained negative (Figure 4B).

\section{Discussion}

The WT1 gene is located on the short arm of chromosome 11, band p13 (3), which consist of 10 exons, and encodes a transcriptional factor that is a zinc-finger protein. FS and Denys-Drash syndrome (DDS) are both caused by specific mutations in WT1 and have similarities. However, the two syndromes have clinical and genetic differences. In DDS, a dominant negative mutation in exons 8 or 9 of WT1 leads to production of abnormal WT protein. The nephropathy is defined by diffuse mesangial sclerosis and manifests generally in the first year of life. Patients with DDS have a high risk of Wilms' tumor of the kidney (4). In contrast, in FS, a point mutation on donor splice site on intron 9 [intervening sequence (IVS 9)] of WT1 leads to nephropathy which appears later in life and is due to focal segmental glomerulosclerosis. Progression to renal failure is slower. The renal pathology of our case is not typical. There is no predisposition to Wilms' tumor in FS but patients have a higher risk of gonadoblastoma, which can be the presenting feature (5).

WT1 is a regulator of early gonadal and renal development (2). Two major WT1 isoforms are produced by alternative splicing of the lysine-threonine-serine (KTS) domain, including an insertion (+KTS) and a deletion (-KTS) (3). In the normal situation, approximately twice as many + KTS as $-\mathrm{KTS}$ isoforms are produced. Intron 9 splice mutation affects the production of $+\mathrm{KTS}$ isoform and impairs the 2:1 ratio for +KTS and-KTS isoforms, respectively, which are important for the normal development of the glomerular podocytes and for male sex determination (6). The +KTS isoform of WT1 participates in RNA processing, and has been shown to play a crucial role in the regulation of sex-determining region $\mathrm{Y}$ (SRY) in vivo in mice $(2,3)$. Thus it can be surmised that WTl or SRY mutations can induce early errors in the process of sex determination mediated by preventing proper formation of the testis. Furthermore, sex reversal is observed in male mice deficient in the +KTS isoform of WT1 (2). In human patients with FS, a point mutation on IVS 9 brings about down-regulation of the +KTS isoform of WT1, which in turn diminishes SRY expression levels (7), thereby impairing testicular development (2). Thus, male to female sex reversal will occur in pediatric patients with FS with 46, XY (8).

The diagnosis of FS is often suspected upon evaluation of primary amenorrhea in patients with end-stage renal disease awaiting kidney transplantation and it is confirmed by demonstrating mutation in the WT1 gene, as in our case.

The gonadoblastoma, composed of germ cells and stromal cells, which is the in situ source of germ cell malignancy of the ovary and dysgenetic gonad, has the potential to progress towards invasive germ cell tumor in $60 \%$ of cases, particularly dysgerminoma, and less frequently towards component of other malignant tumors, such as embryonic 


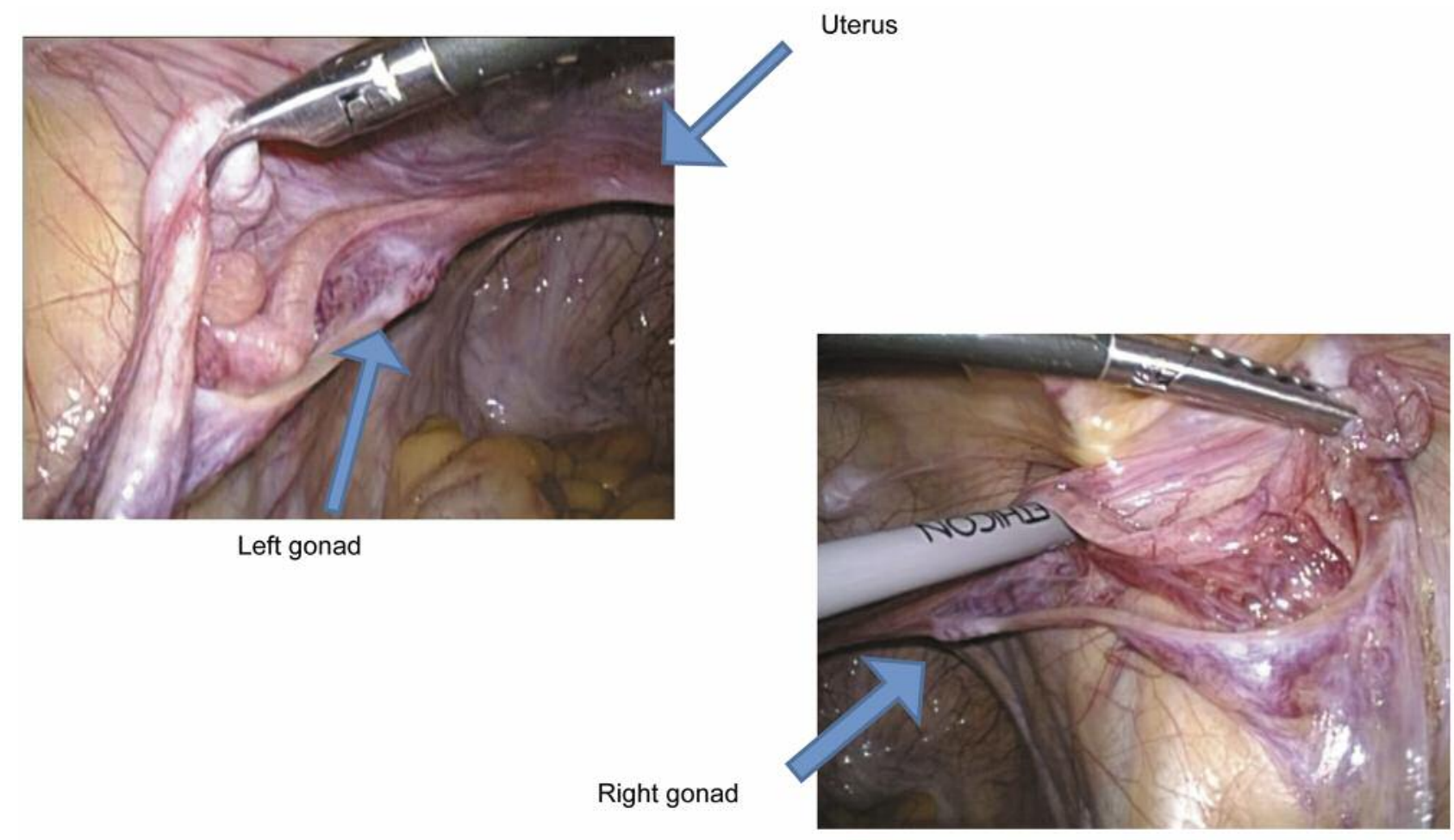

Figure 1. The laparoscopic finding of bilateral streak gonad, fallopian tube and uterus.

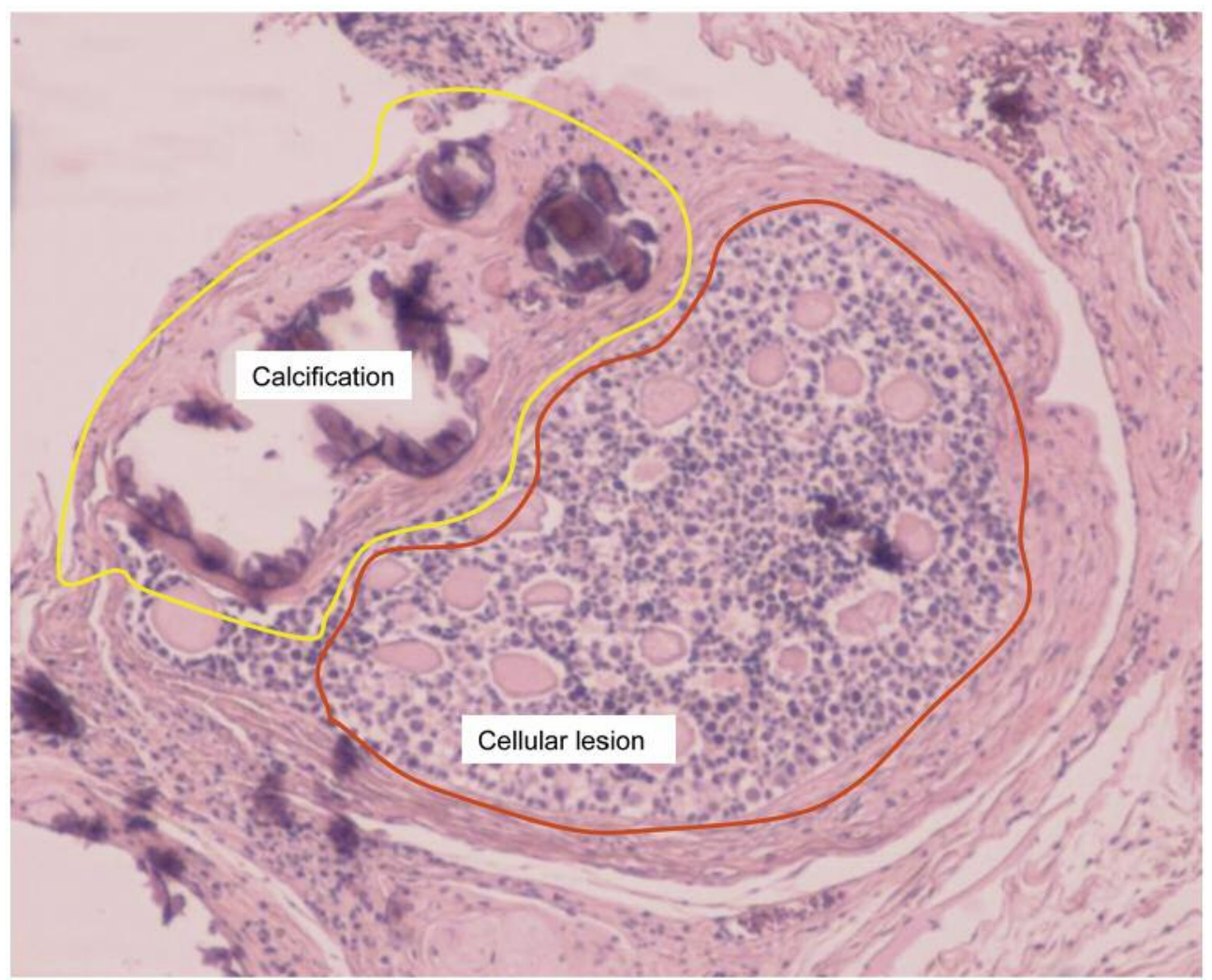

Figure 2. Histopathological finding of a tumor in the right gonad, hematoxylin and eosin staining $(\times 40)$. 


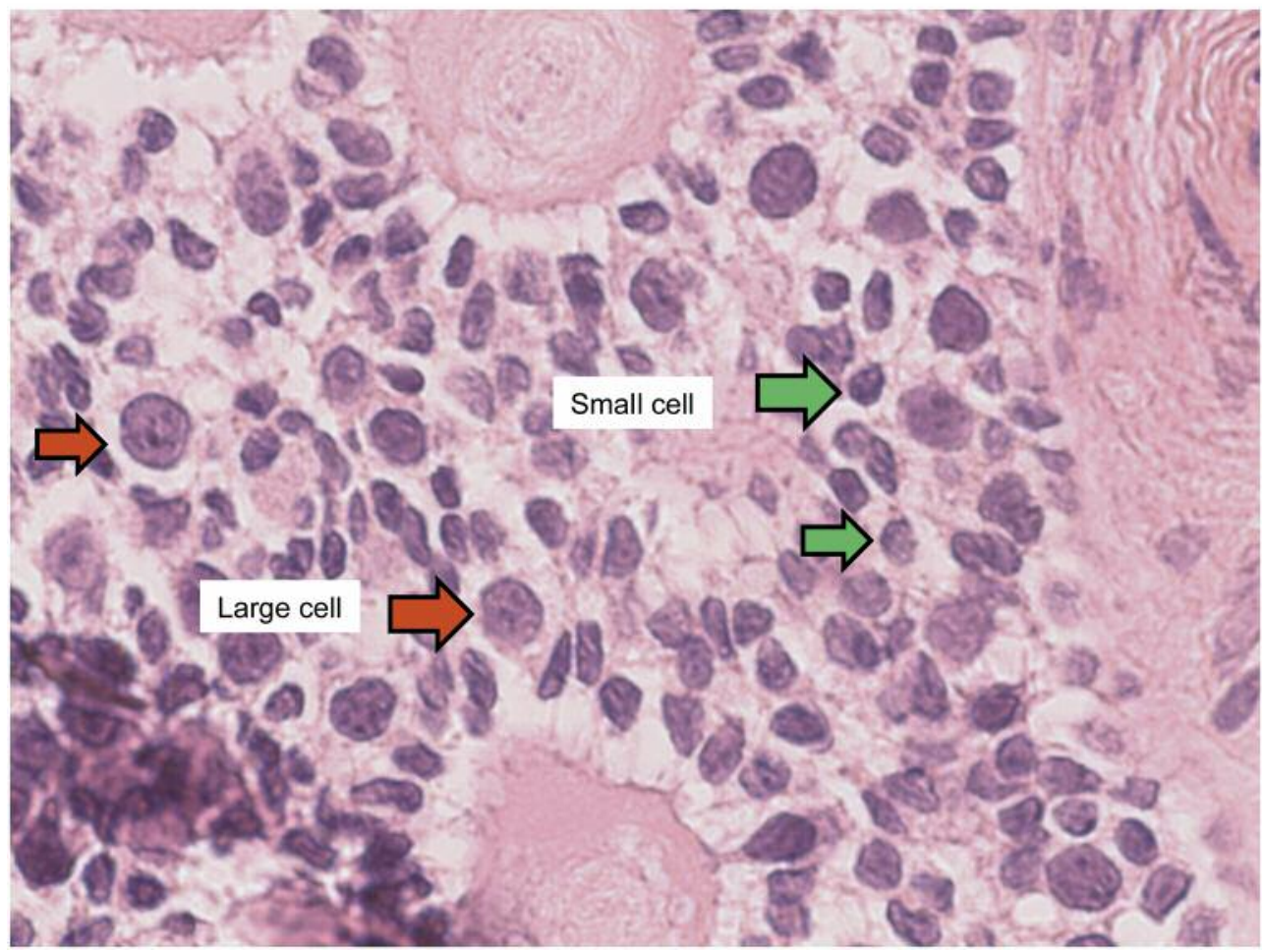

Figure 3. Histopathological finding a tumor in the right gonad, hematoxylin and eosin $(H \& E)$ staining $(\times 100)$.

A

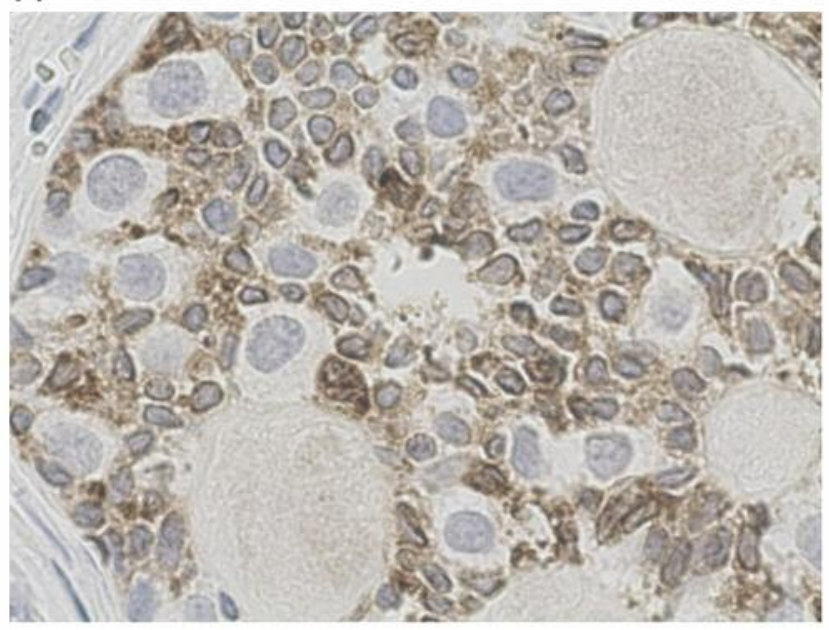

Small cell (sex-cord stroma like)
B

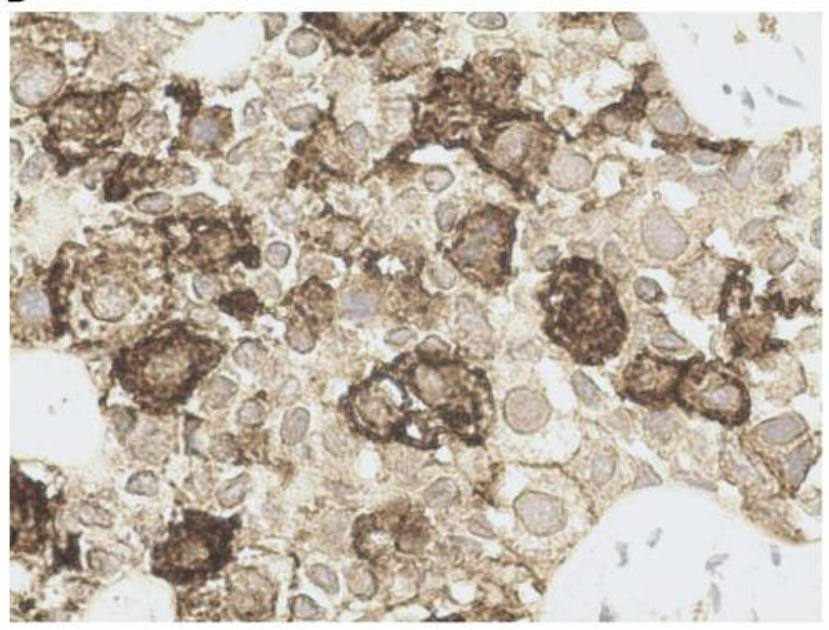

Large cell (germ cell-like)

Figure 4. Immunohistochemical positive staining of $\alpha$-inhibin $(A)(\times 100)$ and placental alkaline phosphatase $(B)(\times 100)$.

carcinoma, yolk sac tumor and choriocarcinoma $(9,10)$. In comparison to other conditions in which male pseudohermaphoroditism is present, the risk of gonadal tumor is particularly high in FS (60\% compared to $40 \%$ for
DDS and $15 \%$ for partial androgen-insensitivity syndrome) (11). Gonadoblastoma commonly occurs in the second decade of life but can develop in children with gonadal dysgenesis as early as 9 months of age (12). 
Therefore, gonadectomy should be considered soon after the diagnosis of streak gonad is made in FS (13). Standard chemotherapy for advanced germ cell malignancy is a combination therapy of bleomycin, etoposide and cisplatin. The limitation of cisplatin use in patients with renal insufficiency is also the reason why early gonadectomy is recommended.

In conclusion, this report emphasizes the need for screening for WT1 mutations in girl with steroid-resistant nephrotic syndrome and prompt prophylactic gonadectomy is recommended if the diagnosis of FS is confirmed. Dual energy X-ray absorptiometry screening and HT are also necessary because long-term steroid use and insufficiency of sex steroid production weaken bone strength, especially leading to low bone mass.

\section{Conflicts of Interest}

The Authors declare no conflicts of interest in regard to this study.

\section{References}

1 Frasier SD, Bashore RA and Mosier HD: Gonadoblastoma associated with pure gonadal dysgenesis in monozygous twins. J Pediatr 64: 740-745, 1964.

2 Hersmus R, van der Zwan YG, Stoop H, Bernard P, Sreenivasan R, Oosterhuis JW, Brüggenwirth HT, de Boer S, Wolffenbuttel KP, Alders M, McElreavy K, Drop SL, Harley VR and Looijenga LH: A 46, XY female DSD patient with bilateral gonadoblastoma, a novel SRY missense mutation combined with a WT1 KTS splice-site mutation. Plos One 7: e40858, 2012.

3 Guaragna MS, Lutaif AC, Bittencourt VB, Piveta CS, Soardi FC, Castro LC, Belangero VM, Maciel-Guerra AT, Guerra-Junior G and Mello MP: Frasier syndrome: four new cases with unusual presentations. Arq Bras Endocrinol Metabol 56: 525-532, 2011.

4 Saylam K and SimonP: WT1 gene mutation responsible for male sex reversal and renal failure: the Frasier syndrome. Eur J Obstet Gynecol Reprod Biol 110: 111-113, 2003.
5 Koziell A and Grundy R: Frasier and Denys-Drash syndrome: Different disorders or part of a spectrum? Arch Dis Child 81: 365-369, 1999.

6 Bruening W, Bardeesy N, Silverman BL, Cohn RA, Machin GA, Aronson AJ, Housman D and Pelletier J: Germline intronic and exonic mutations in the Wilms' tumor gene (WT1) affecting urogenital development. Nat Genet 1: 144-148, 1992.

7 Schumacher V, Gueler B, Looijenga LH, Becker JU, Amann K, Enger R, Dotsch J, Stoop H, Schulz W and Rover-Pokora B: Characteristics of testicular dysgenesis syndrome and decreased expression of SRY and SOX9 in Frasier syndrome. Mol Reprod Dev 75: 1484-1494, 2008.

8 Love JD, Demartini SD and Coppola CP: Prophylactic bilateral salpingo-oophorectomy in a 17 -year-old with Frasier syndrome reveals gonadoblastoma and seminoma: a case report. J Pediatr Surg 41: e1-4, 2006.

9 Saenger P: Clinical review 48: The current status of diagnosis and therapeutic intervention in Turner's syndrome. J Clin Endocrinol Metab 77: 297-301, 1993.

10 Looijenga LH, Stoop H, de Leeuw HP, de Gouveia Brazao CA, Gillis AJ, van Roozendaal KE, van Zoelen EJ, Weber RF, Wolffenbuttel KP, van Dekken H, Honecker F, Bokemeyer C, Perlman EJ, Schneider DT, Kononen J, Sauter G and Oosterhuis JW: POU5F1 (OCT3/4) identifies cells with pluripotent potential in human germ cell tumors. Cancer Res 63: 2244-2250, 2003.

11 Pleskacova J, Hersmus R, Oosterhuis JW, Setyawati BA, Faradz SM, Cools M, Wolffenbuttel KP, Lebl J, Drop SL and Looijenga LH: Tumor risk in disorders of sex development. Sex Dev 4: 259-269, 2010.

12 Dumić M, Jukić S, Batinica S, Ille J and Filipović-Grcić B: Bilateral gonadoblastoma in 9-month-old infant with 46, XY gonadal dysgenesis. J Endocrinol Invest 16: 291-293, 1993.

13 Hughes IA, Houk C, Ahmed SF and Lee PA: Consensus statement on management of intersex disorders. J Pediatr Urol 2: 148-162, 2006. 